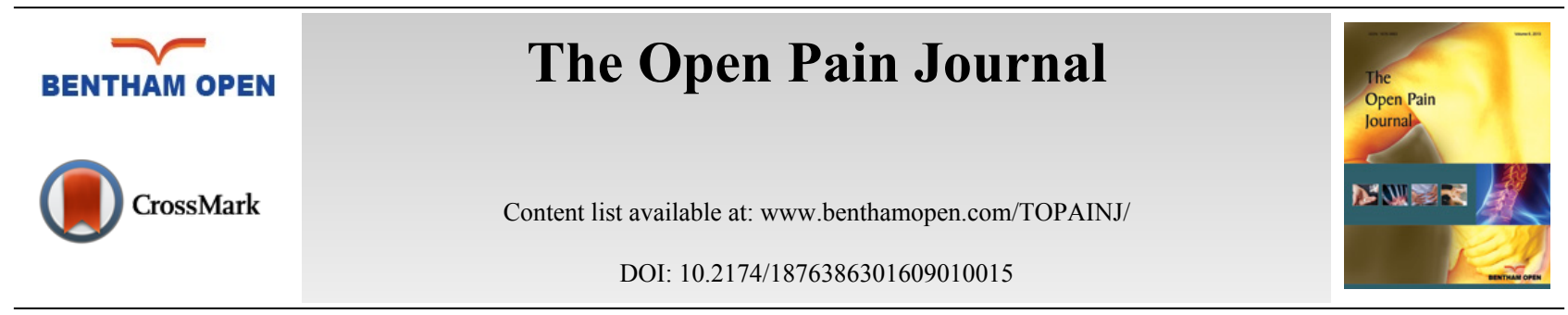

RESEARCH ARTICLE

\title{
Hyperuricemia is Associated with Musculo-skeletal Pain - Results from a Cross-sectional Study
}

\author{
Hans-Ulrich Comberg ${ }^{1, *}$ and Siegfried Schach ${ }^{2}$ \\ 'General and Family Medicine, Jürgensallee 4222609 Hamburg, Germany \\ ${ }^{2}$ Department of Statistics, TU Dortmund 44227 Dortmund, Germany
}

Received: October 21, 2015

Revised: June 30, 2016

Accepted: July 19, 2016

\begin{abstract}
:
Background:

The use of urate lowering therapy in patients without gouty arthritis and slightly elevated uric acid levels (so called "asymptomatic" hyperuricemia) is still under debate.
\end{abstract}

\section{Introduction/Objectives:}

This study explores whether slightly elevated urate levels are associated with musculo-skeletal pain.

\section{Method:}

This cross-sectional study was conducted in a single German center. Generally healthy subjects (including patients with controlled mild hypertension, hyperlipidemia, and/or not insulin dependent type 2 diabetes) aged 20-75 years presenting for their annual routine check-up were invited to participate. Documented parameters included a full blood count, blood pressure, weight, height, prescribed medication, purine and alcohol intake, and pain assessment during the two preceding years.

The sample size was determined by the requirement that in comparing major groups (such as men vs. women, hyperuricemia $v s$. normal uric levels) a difference between these groups in an attribute (such as joint pain) should be discovered with a probability of at least 90 percent.

\section{Results:}

In total, 600 patients $(54.7 \%)$ male, $(55.2 \% \pm 137$ years $)$ were included in the survey. Urate levels were closely correlated to the number of patients complaining about joint pain $(\mathrm{r}=0.978)$. Higher urate levels were associated with a higher percentage of patients with joint pain. There was a marked increase in the percentage of patients experiencing joint pain from urate level 5 (30.8\%) to 5.5 (60.9\%). Lumbar spine, cervical spine, shoulder, and knee were the most common locations for joint pain. Multivariate analysis indicated weight, purine intake, alcohol consumption, administration of diuretics, creatinine, and triglycerides as factors with significant impact on the urate level. Of all tested variables, only serum urate had a significant impact on joint pain (OR 1.996; 95\% CI 1.626-2.451; $\mathrm{p}<0.0001)$. A significant correlation between pain in various joints and urate levels was found for all most commonly affected regions.

\section{Conclusion:}

In this population of generally healthy subjects presenting for their annual routine check-up, results indicate the possibility of a significant impact of urate levels on joint pain.

Keywords: Asymptomatic hyperuricemia, Gout, Musculo-skeletal pain, Serum urate.

\footnotetext{
* Address correspondence to this author at the General Family Medicine, Jürgensallee 42, 22609 Hamburg, Germany; Tel: ++49 40 823534; E-mail:
} dr.comberg@t-online.de 


\section{INTRODUCTION}

Episodes of diffuse musculo-skeletal pain appearing in and around a joint region without a clear diagnosis, etiology and therapy are still a major problem in general medicine. A clear diagnosed gout is the most common inflammatory arthritic disease, affecting about $1 \%$ to $2 \%$ of the population [1]. Prevalence is expected to increase due to changes in diet - such as high intake of meat, fructose and beer - and the ageing of the population [2]. Clinically, gout is defined as a deposition disease, i.e. diagnosis is confirmed by the presence of monosodium urate crystals in the synovial fluid or tophi in soft tissue [1]. These crystals are responsible for acute episodes of inflammation as well as long-term sequelae due to chronic inflammation of gout [3].

The deposition of monosodium urate results from untreated hyperuricemia. The crystallization process is temperature and $\mathrm{pH}$-dependent and occurs when the theoretical saturation threshold of $6.8 \mathrm{mg} / \mathrm{dL}(\sim 400 \mu \mathrm{mol} / \mathrm{L})$ serum urate at $37^{\circ} \mathrm{C}$ is exceeded [4]. Accordingly, lowering the serum urate level and depleting the body urate pool are the established goals in the treatment of gout. To achieve this, the serum urate must be reduced below the saturation point of monosodium urate under physiological conditions. Based on these conclusions, the European League against Rheumatism (EULAR) and American Society of Rheumatism Task Forces for Gout recommend lowering serum urate levels to a target of $\leq 6 \mathrm{mg} / \mathrm{dL}(360 \mu \mathrm{mol} / \mathrm{L})[5,6]$. For patients with tophaceous disease manifestation, the British Society of Rheumatology (BSR) and American College of Rheumatology (ACR) proposed an even stricter serum urate target of $<5 \mathrm{mg} / \mathrm{dL}(<300 \mu \mathrm{mol} / \mathrm{L})[5,7]$. Hence, the establishment of a target value results from biochemical observations, i.e. the crystallization process, and not from epidemiological results.

Although hyperuricemia is an established risk factor for gout with a prevalence in the US of more than $21 \%[8,9]$ there is still debate regarding the diagnostic value of serum urate levels. There are case reports indicating that many people with higher serum urate levels do not develop gout, while others presenting with crystal proven gout have "nearly" normal serum urate levels at the time of investigation [10]. While the usefulness of urate-lowering treatment in patients with clinical manifestations of hyperuricemia has been established, its use in asymptomatic hyperuricemia is still the object of several controversies [11]. Nevertheless evidence rises for uric acid in non-gouty patients to be an independent cardiovascular and metabolic risk factor. Asymptomatic hyperuricemia is both associated with as well as a predictor of hypertension, renal deficiency and diabetes. Therefore, uric acid is increasingly seen as part of the metabolic syndrome [12].

Since evidence for subclinical musculo-skeletal involvement in otherwise asymptomatic individuals with hyperuricemia is lacking, urate lowering therapy to date is only indicated and reimbursed in cases of confirmed gout. Current international guidelines do not address the pharmacologic management of asymptomatic hyperuricemia due to a paucity of prospective, randomized, controlled intervention trials in that area [13]. Still there are no data available how many patients with asymptomatic hyperuricemia have to be treated to prevent one patient with gout (number needed to treat/number needed to harm). However, in a cross-sectional controlled study ultrasound findings demonstrate the signs of present monosodium urate crystal tissue deposition in both intra and extra-articular structures from asymptomatic hyperuremic individuals [14]. The present study addresses the issue whether slightly elevated urate levels are associated with musculo-skeletal pain.

\section{METHODS}

\section{Study Design}

The association between hyperuricemia and musculo-skeletal pain was explored in a cross-sectional study conducted at a single German center from August 1999 to December 2001. This study was reviewed and approved by federal state law established Ethics Committees Counselling (reference no. OB.99).

\section{Participants}

Generally healthy subjects (including patients with controlled mild hypertension, hyperlipidemia, and or not insulin dependent diabetes) aged between 20 and 75 years who visited their general practitioner for their annual check-up were invited to participate in the survey. Patients having one of the following conditions were not eligible for participation: bone diseases (eg. tumors, metastasis, osteoporosis), any malignancy, systemic inflammatory disorders (such as rheumatoid arthritis, ulcerative colitis, Crohn's disease, ankylosing spondylitis, polymyalgia rheumatica, and autoimmune thyroiditis), localized inflammations (such as tenosynovitis, bursitis, epicondylitis, and erysipelas), acute 
infections (such as common cold, bronchitis, and urinary tract infection) including those which resolved within 4 weeks prior to enrolment, peripheral artery disease ( $\geq$ stage IIb), venous ulcer, peripheral neuralgia, ischialgia, invasive procedures performed within the last 4 weeks, vaccinations received within 1 week prior to enrolment, intramuscular injections received within 1 week prior to enrolment. Poorly controlled patients or with renal insufficiency were not included.

\section{Documentation}

After informed consent, data were obtained by patient interviews and documented in a standardized questionnaire. All disease history-related questions were documented by the examining physician. In order to minimize bias, laboratory check-ups were performed by residents, who were not more familiar with the patient. Documented parameters included age, gender, weight, height, blood pressure, urate level, erythrocyte sedimentation rate (ESR), hypersensitive CRP (S-CRP), total cholesterol, high-density lipoprotein (HDL), low-density lipoprotein (LDL), creatinine, blood glucose, triglycerides, daily consumption of alcohol, meat consumption (purine intake), diuretics, other antihypertensive drugs, lipid-lowering agents, and antidiabetic drugs.

Joint pain was measured based on patients report. In case of a positive statement for permanent or recurrent pain within the musculo-skeletal system localization was documented (joint regions). Pain duration within 19 pre-selected locations (Table 1) was documented according to the patient's statement. Data were totaled in case of multiple occurrences at the same location.

Table 1. Pre-selected joint regions for pain assessment.

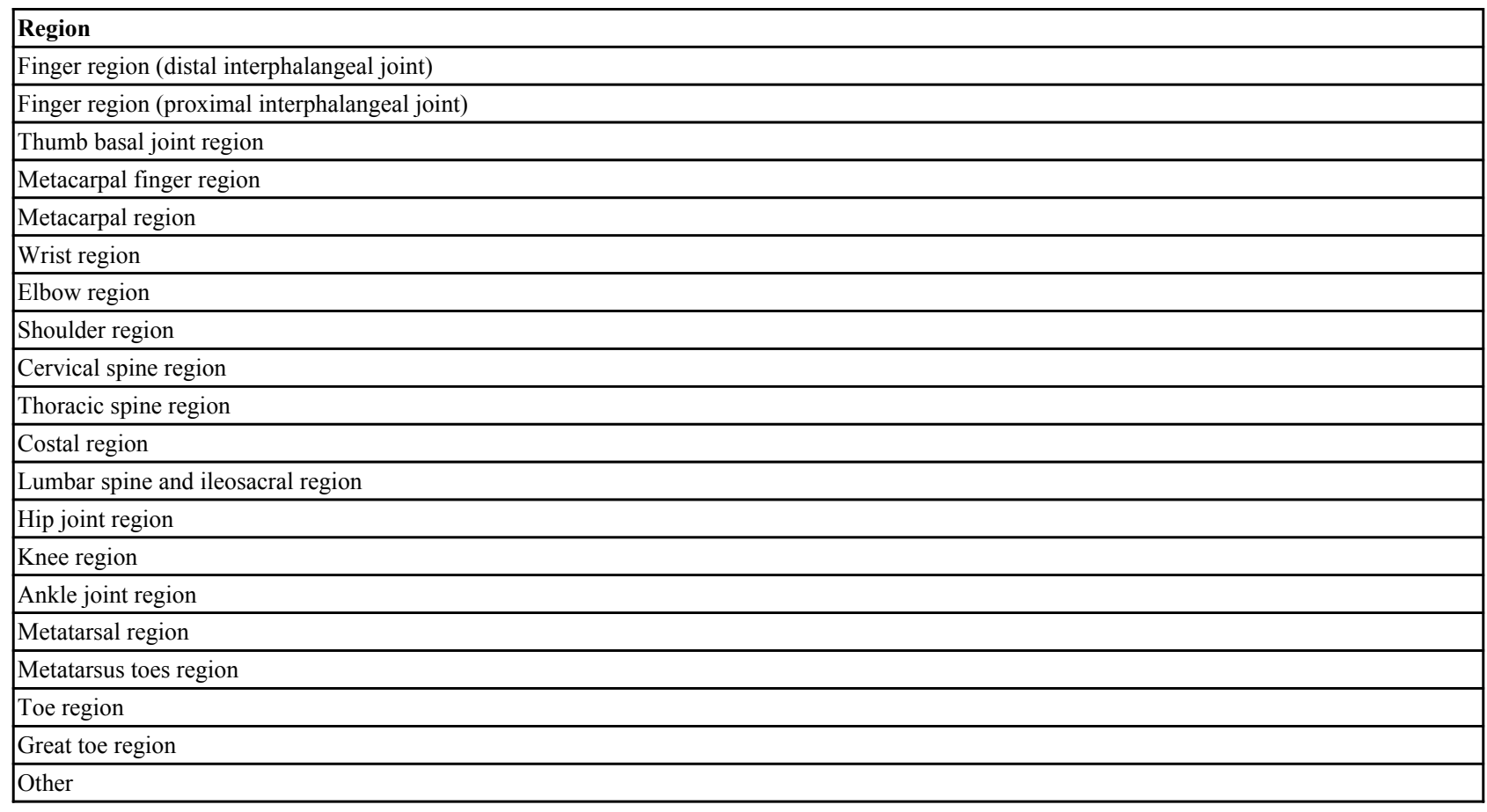

Since patients with bone diseases or systemic inflammatory disorders were excluded from the study pain is much better described by idiopathic arthralgia than arthritis. Clinical examination of specified locations with pain regularly did not support another diagnose.

Values of routinely acquired blood samples were obtained after a fasting period of $\geq 6 \mathrm{~h}$. Pain history, prescribed medication, consumption of alcohol and purine during the two preceding years were inquired. For the calculation of purine intake from meat, the following definitions were applied: One meat dish corresponded to $240 \mathrm{mg}$ purine and one sausage sandwich corresponded to $55 \mathrm{mg}$ purine [15].

\section{Statistical Analyses}

All data analyses were carried out according to a pre-established analysis plan. The collected data were analyzed with descriptive methods, using SAS 8.2 (SAS Institute Inc., Cary, NC, USA). Pearson correlation was used for the 
evaluation of relationships between parameters. Odds ratios were calculated by means of multiple logistic regression. All tests were two-sided, and significance was declared at the 0.05 level, unless stated otherwise.

The sample size was determined by the requirement that in comparing major groups (such as men vs. women, hyperuricemia vs. normal uric levels) a difference between these groups in an attribute (such as joint pain) should be discovered with a probability of at least 90 percent.

\section{RESULTS}

\section{Patient Disposition and Baseline Characteristics}

In total, 600 patients were included in the survey. Gender ratio was balanced (54.7\% male). About $50 \%$ of patients were between 50 and 69 years old (mean $55.2 \pm 13.7$ years, 95\% CI 54.1-56.3). Mean body mass index (25.4 \pm 15.5 $\mathrm{kg} / \mathrm{m}^{2}, 95 \%$ CI 25.1-25.8) was lower in females compared to their male counterparts of the same age group and increased slightly with age.

Mean purine intake from meat and sausage (148.8 $\pm 87.8 \mathrm{mg} / \mathrm{d}, 95 \%$ CI 141.9-155.8) was markedly higher in males across all age groups. There was a slight decrease with increasing age, particularly in men. Mean alcohol consumption was $17.7 \pm 20.8 \mathrm{~g} / \mathrm{d}$ (95\% CI 16.0-19.3). Overall, there was a rise in alcohol consumption with age, whereby alcohol ingestion was noticeably lower in females compared to males.

286 out of 600 patients (47.7\%) experienced joint pain during the preceding two years. Lumbar spine (195 patients), cervical spine (72 patients), shoulder (63 patients), and knee (51 patients) were the most common locations for joint pain. The shoulder was the region with the longest period of pain (mean duration 74.9 days), followed by cervical spine (57.2 days), lumbar spine (48.6 days), and knee (37.3 days) (Fig. 1). For the other joint regions, patient numbers were too low for statistical analysis (elbow region $n=20$, thoracic spine region $n=12$, ankle joint region $n=10$, wrist region $\mathrm{n}=9$, other regions $\mathrm{n} \leq 5$ ); therefore, these were not studied in detail.

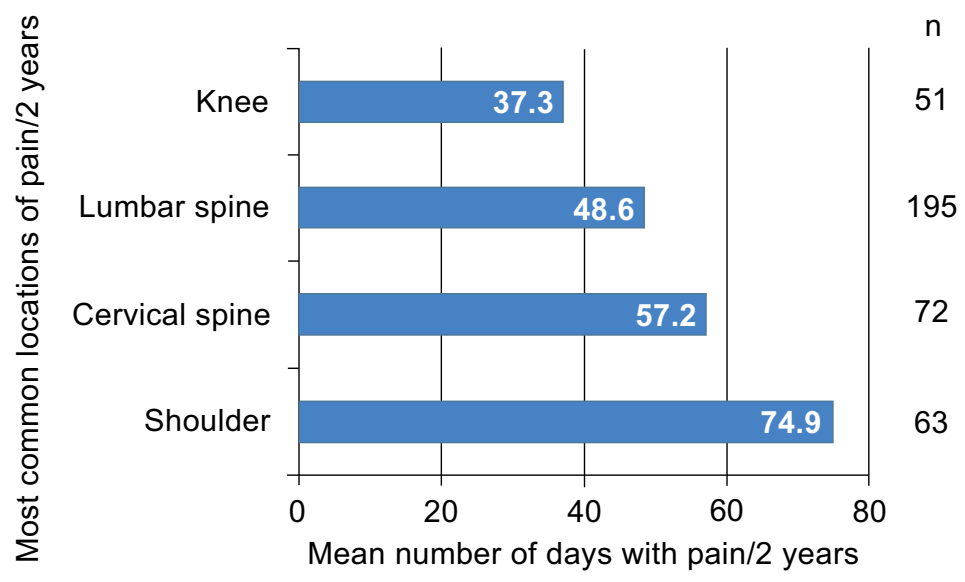

Fig. (1). Most common locations of joint pain and mean duration of pain in days during the two preceding years.

In women, serum urate levels increased with age, while males showed more or less constant serum urate levels around the $6 \mathrm{mg} / \mathrm{dl}(360 \mu \mathrm{mol} / \mathrm{L})$ level (Fig. 2). Urate levels were closely correlated to the number of patients complaining about joint pain $(\mathrm{r}=0.978)$. Higher urate levels were associated with a higher percentage of patients with joint pain (Fig. 3). There was a marked increase in the percentage of patients experiencing joint pain from urate level 5 $(30.8 \%)$ to $5.5(60.9 \%)$.

In our trial hyperuricemia was defined as uric acid levels exceeding $6 \mathrm{mg} / \mathrm{dl}$ for men or $5 \mathrm{mg} / \mathrm{dl}$ for women. The number of joints affected with pain was significantly higher in persons with hyperuricemia as compared to persons with normal uric acid levels. This holds true for men and for women $(p<0.001)$. Figs. $(4$ and 5$)$ show that the number of affected joints with pain tends to rise in hyperuricemic patients. This seems to be more pronounced in women than in men. 


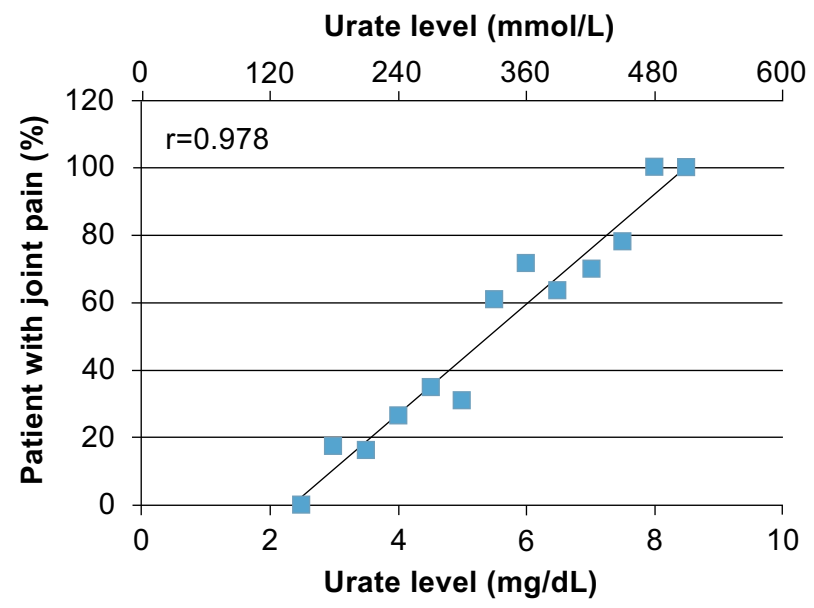

Fig. (2). Mean urate levels stratified by age groups.

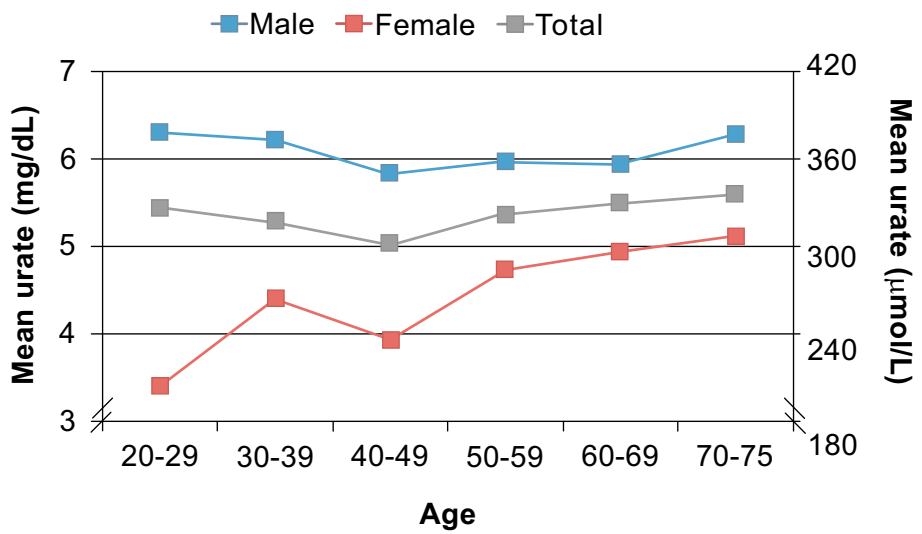

Fig. (3). Correlation between urate level and prevalent joint pain.

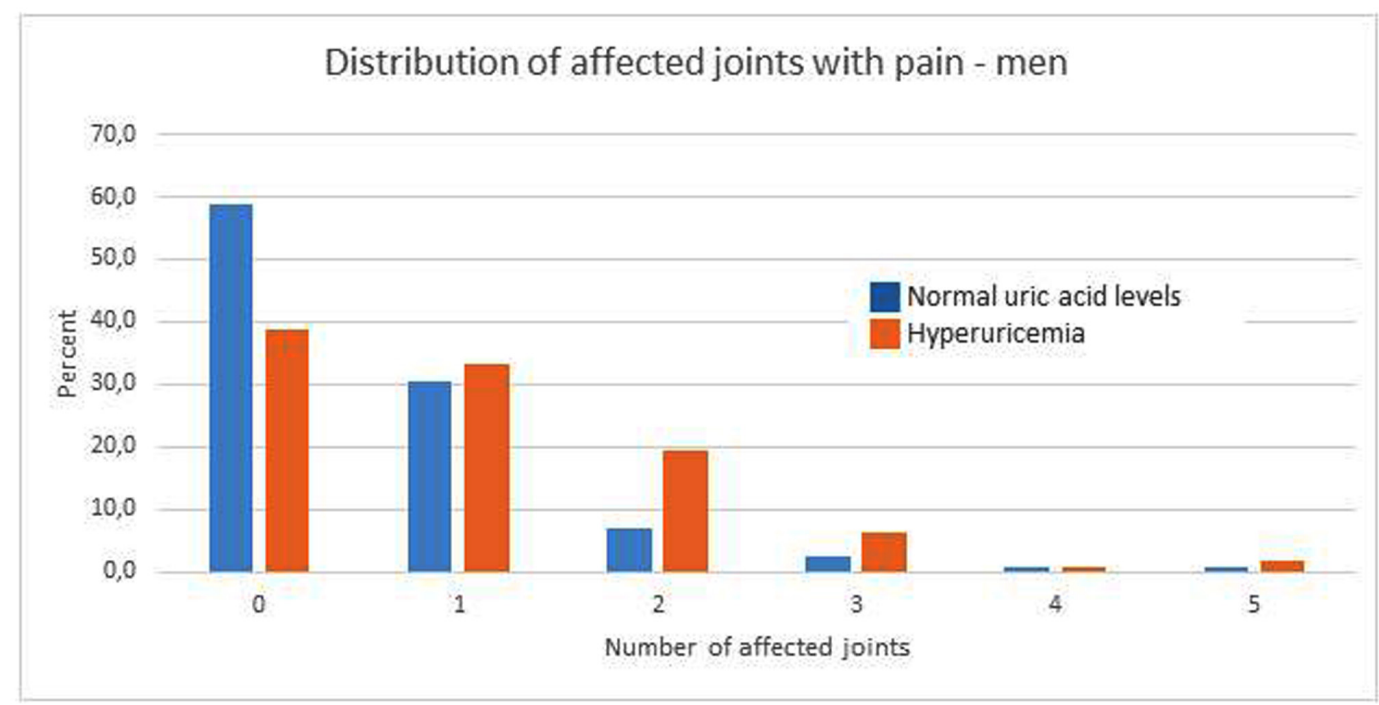

Fig. (4). Distribution of affected joints with pain - men $(\mathrm{p}<0.001)$. 


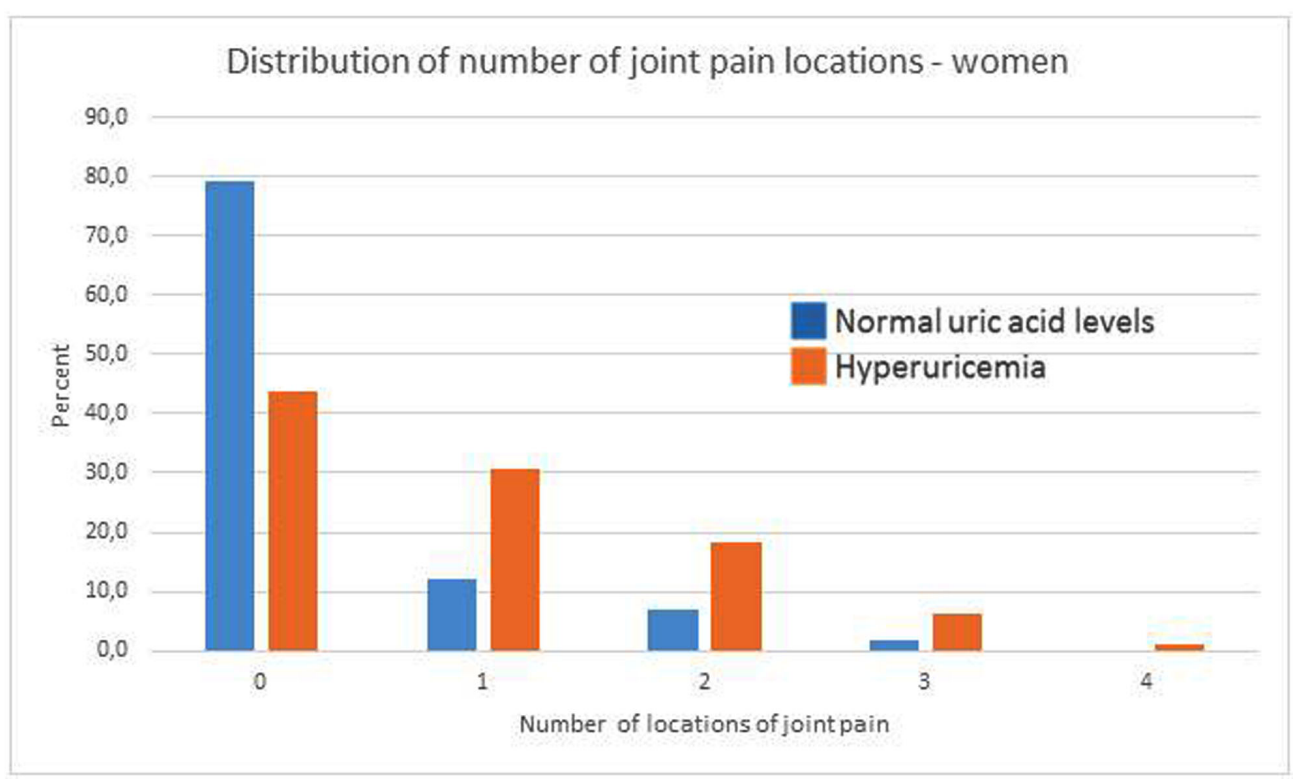

Fig. (5). Distribution of affected joints with pain - women $(\mathrm{p}<0.001)$.

\section{Impact of Other Factors on Urate Level and Joint Pain}

All documented parameters were analyzed for their impact on the urate level. Multivariate analysis using urate level as dependent variable indicated weight, purine intake, alcohol consumption, administration of diuretics, creatinine, and triglycerides as factors with significant impact on the urate level (Table 2).

Table 2. Impact of different factors on the urate level.

\begin{tabular}{|c|c|c|}
\hline Variable & Regression coefficient & $\mathbf{p}$ \\
\hline S-CRP & 0.0091 & 0.6893 \\
\hline Age & 0.0033 & 0.4378 \\
\hline Weight & 0.0240 & $<0.0001$ \\
\hline BMI & 0.0141 & 0.5326 \\
\hline Purine intake & 0.0017 & 0.0006 \\
\hline Alcohol consumption & 0.0066 & 0.0023 \\
\hline Diuretics & 0.4985 & 0.0015 \\
\hline Lipid-lowering agents & 0.0046 & 0.9772 \\
\hline ESR & -0.0014 & 0.9003 \\
\hline Systolic blood pressure & 0.0021 & 0.5805 \\
\hline Diastolic blood pressure & -0.0033 & 0.6052 \\
\hline Antihypertensive drugs (other than diuretics) & -0.0113 & 0.9294 \\
\hline Antidiabetic drugs & -0.4903 & 0.1264 \\
\hline Creatinine & 2.0646 & $<0.0001$ \\
\hline Glucose & -0.0011 & 0.6063 \\
\hline Total cholesterol & 0.0023 & 0.4624 \\
\hline HDL & -0.0071 & 0.1152 \\
\hline LDL & -0.0006 & 0.8469 \\
\hline Triglycerides & 0.0034 & $<0.0001$ \\
\hline
\end{tabular}

Using multivariate logistic regression analysis, the impact of various factors on joint pain was evaluated. Of all tested variables, only serum urate had a significant impact (OR 1.996 (95\% CI 1.626-2.451; p < 0.0001) on joint pain (Fig. 6). Among the factors analyzed, serum urate is the variable with the highest predictive power. If the urate level of a person is known, knowledge of additional variables, such as age, will not affect the probability for joint pain substantially. A correlation between pain in various joints and urate levels was found for all most commonly affected regions ( $p<0.0001$ for shoulder, lumbar spine and knee; $p=0.0003$ for cervical spine). Fig. (7) illustrates this correlation 
for lumbar spine pain. Across all age groups $>40$ years patients experiencing pain have higher urate levels compared to pain-free patients.

The study population was subdivided into patients with hyperuricemia and with normal uric acid levels. Hyperuricemia was defined as uric acid level exceeding $6 \mathrm{mg} / \mathrm{dl}$ for men or $5 \mathrm{mg} / \mathrm{dl}$ for women.

The difference between men and women in the prevalence of uricemia is highly significant $(p<0.001$, based on Pearson's test) despite the fact that the cutoff for men was higher than for women.

Females and males with hyperuricemia had a significantly higher body weight, BMI and blood pressure. In addition females with hyperuricemia were significantly older than women with normal uric acid levels (Table $\mathbf{3}$ ).

\begin{tabular}{|c|c|c|c|c|c|}
\hline \multirow[t]{2}{*}{ Parameter } & \multicolumn{4}{|c|}{ OR $(95 \% \mathrm{Cl})$} & \multirow[b]{3}{*}{$<0.0001$} \\
\hline & -0.51 & 1.52 & 2.53 & 3.5 & \\
\hline Serum urate & \multicolumn{4}{|c|}{$1.626 \stackrel{1.996}{2} 2.451$} & \\
\hline Age & \multicolumn{4}{|c|}{$0.988^{1.006} 1.025$} & 0.5189 \\
\hline Weight & \multicolumn{4}{|c|}{$0.9628^{\mathbf{0 . 9 8 8}} 1.014$} & 0.3738 \\
\hline BMI & \multicolumn{4}{|c|}{$\begin{array}{l}1.023 \\
0.927\end{array}$} & 0.6477 \\
\hline Purine intake & \multicolumn{4}{|c|}{$0.999^{1.001} 1.003$} & 0.3987 \\
\hline Alcohol consumption & \multicolumn{4}{|c|}{$0.993^{1.002} 1.012$} & 0.6457 \\
\hline Diuretics & \multicolumn{4}{|c|}{$0.564 \longmapsto 1.121$} & 0.7442 \\
\hline Lipid-lowering agents & \multirow{2}{*}{\multicolumn{4}{|c|}{0.882}} & 0.1074 \\
\hline S-CRP & & & & & 0.8162 \\
\hline Systolic blood pressure & \multicolumn{4}{|c|}{$\begin{array}{l}1.996 \\
0.979^{1.013}\end{array}$} & 0.6493 \\
\hline Diastolic blood pressure & \multicolumn{4}{|c|}{$0.998^{1.026} 1.056$} & 0.0715 \\
\hline Antihypertensive drugs & \multicolumn{4}{|c|}{$0.459 \stackrel{0.797}{1} 1.387$} & 0.4225 \\
\hline Creatinine & \multicolumn{4}{|l|}{$0.216 \longmapsto \mathbf{0 . 7 4 7}$} & 0.6451 \\
\hline HDL & \multicolumn{4}{|c|}{$0.973^{0.986} 1.001$} & 0.0643 \\
\hline LDL & \multicolumn{4}{|c|}{$\begin{array}{l}1.004 \\
0.998 \\
1.009\end{array}$} & 0.1999 \\
\hline Triglycerides & \multicolumn{4}{|c|}{$\begin{array}{c}0.999 \\
0.996 \\
1.002\end{array}$} & 0.6783 \\
\hline
\end{tabular}

Fig. (6). Odds ratio for joint pain.

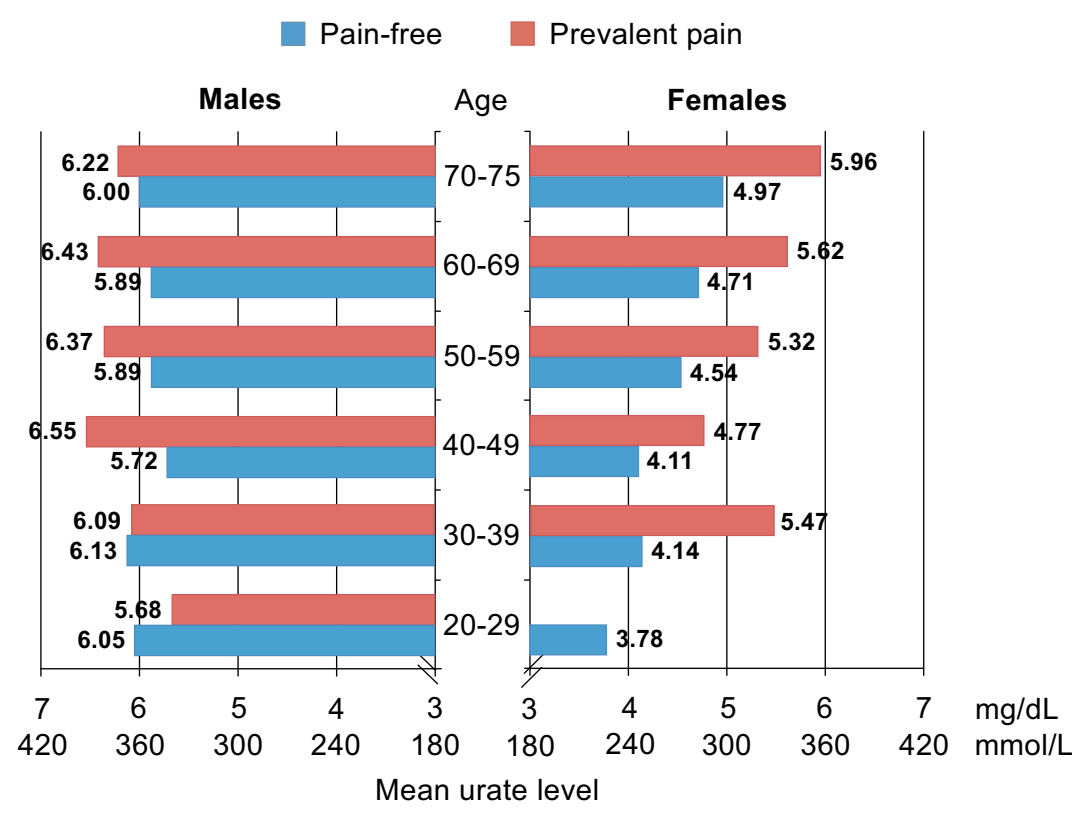

Fig. (7). Mean urate levels in patients with and without pain in the lumbar spine region, stratified by age and gender. 
Table 3. Patient characteristics by uric acid level.

\begin{tabular}{|l|l|l|l|l|}
\hline & & Hyperuricemia & Normal Uric Acid Levels & p-value \\
\hline Both sexes (n) & & $238(43.0 \%)$ & $342(57.0 \%)$ & \\
\hline & & & & \\
\hline Female (n) & & $98(36.0 \%)$ & $174(64.0 \%)$ & \\
\hline & & Mean \pm SE & Mean \pm SE & \\
\hline & $60.0 \pm 1.25$ & $52.7 \pm 0.99$ & $<0.0001$ \\
\hline & Age (years) & $73.7 \pm 1.51$ & $63.8 \pm 0.76$ & $<0.0001$ \\
\hline & Weight (kg) & $27.1 \pm 0.50$ & $22.8 \pm 0.26$ & $<0.0001$ \\
\hline & BMI & $146.7 \pm 1.44$ & $133.9 \pm 2.03$ & $<0.0001$ \\
\hline & Syst. BP (mmHg) & $92.1 \pm 1.15$ & $86.1 \pm 0.81$ & $<0.0001$ \\
\hline & Diast. BP (mmHg) & & & \\
\hline & & $160(48.8 \%)$ & $168(51.2 \%)$ & \\
\hline & & Mean \pm SE & Mean \pm SE & \\
\hline & & $56.3 \pm 1.02$ & $54.6 \pm 0.99$ & $\mathrm{P}=0.1136$ \\
\hline & Age (years) & $86.2 \pm 1.18$ & $81.9 \pm 0.87$ & $\mathrm{P}=0.0015$ \\
\hline & Weight $(\mathrm{kg})$ & $27.2 \pm 0.348$ & $25.4 \pm 0.248$ & $\mathrm{P}<0.0001$ \\
\hline & BMI & $143.3 \pm 1.40$ & $138.0 \pm 1.51$ & $\mathrm{P}=0.0052$ \\
\hline & Syst. BP $(\mathrm{mmHg})$ & $91.2 \pm 0.995$ & $88.8 \pm 0.804$ & $\mathrm{P}=0.0181$ \\
\hline
\end{tabular}

$\mathrm{SE}=$ Standard error or the mean

The study population was subdivided into patients with hyperuricemia and with normal uric acid levels. Hyperuricemia was defined as uric acid level exceeding $6 \mathrm{mg} / \mathrm{dl}$ for men or $5 \mathrm{mg} / \mathrm{dl}$ for women. The difference between men and women in the prevalence of uricemia is highly significant ( $\mathrm{p}<$ 0.001 , based on Pearson's test) despite the fact that the cutoff for men was higher than for women.

\section{DISCUSSION}

The present cross-sectional study evaluated the relationship between hyperuricemia and musculo-skeletal pain. In this population of generally healthy subjects (including patients with controlled mild hypertension, hyperlipidemia, and /or not insulin dependent diabetes) presenting for their annual routine check-up, mean urate levels were within the normal to slightly elevated range, whereby both, men and women, showed an increase with age, which was much stronger in women. Results indicate a possible impact of the urate level on unspecific joint pain. This correlation was significant for overall joint pain as well as for the most commonly pain-affected locations lumbar spine, cervical spine, shoulder, and knee. A comparison of urate levels demonstrated consistently higher urate levels in patients experiencing joint pain than in pain-free patients, independent of gender and across the relevant age group $>40$ years, which covers the broad majority of this population. A similar relationship between urate level and musculo-skeletal pain was indicated in a 1-year longitudinal study linking urate levels in women with chronic non-gouty pain to the number of pain locations [16]. The authors suggested more intensive care and rehabilitation measures for patients featuring a relatively high serum urate level, yet still within the reference range, along with pain at multiple locations [16].

Triggered by the crystallization of urate within the joints, gout can lead to substantial morbidity by causing severe pain. While the role of hyperuricemia in the manifestation of gout is established, it is still under debate whether elevated urate levels alone are already an indication to start anti-gout treatment. According to the developed evidence-based recommendations for the diagnosis and management of gout $[1,5,6]$ a raised serum urate level alone is not specific to gout $[1,6]$. Nevertheless the degree of hyperuricemia is a strong predictor for an increased risk to develop gout [9]. Rheumatologic guidelines recommend a target value for uric acid in gout patients (men and women) of $<6 \mathrm{mg} / \mathrm{dl}$ [ 5 7].

Emerging evidence suggests that gout is independently associated with all-cause mortality $[8,17,18]$ as well as cardiovascular mortality [19]. Furthermore, several studies demonstrated that elevated urate levels were associated with an increased risk for cardiovascular mortality in CKD patients [20 - 22], thus strengthening the necessity to lower urate before the development of gout. Notably, for the first time, Stack et al. provided evidence in a population-based cohort trial that not only gout but also hyperuricemia alone is associated with total and cardiovascular mortality. In this context, other epidemiological studies indicated that an elevated serum urate level alone is an independent predictor of the development of chronic kidney disease (CKD) in patients with normal renal function [23] and progression of renal disease in hyperuricemic patients achieving uric acid lowering therapy could be decelerated [24]. Consequently, several interventional studies showed beneficial effects of urate lowering therapies. 
The potential additional benefits of urate lowering therapy before the manifestation of gout outlined above are backed up by ultrasonographic findings. In a cross-sectional controlled study morphostructural changes suggestive for monosodium urate deposition induced by chronic hyperuricemia were found in both intra- and extra-articular structures of clinically asymptomatic individuals [14]. Similarly, ultrasonographic examinations of patients with asymptomatic hyperuricemia revealed sonographic findings implicating an as yet silent precipitation of urate crystals [25]. This corresponds to our observation that high-sensitive CRP does not correlate with an increase in urate level and pain. Therefore, one possible crystal-mediated inflammation appears to be of a nature that is not perceptible by serological findings. In addition, crystal-independent mechanisms might be involved. Oxidative pathways seem to participate in local and systemic damage to joints. The damage seems to be based on the increased activity of xanthine oxidase in hyperuricemia, resulting in the production of reactive oxygen species (ROS) [26]. It is noteworthy that ROS generated via activated xanthine oxidase is also playing a major role in the cardio-renal-metabolic syndrome [27].

In both ultrasonographic studies, patients with asymptomatic hyperuricemia had a mean urate level of $8.1 \mathrm{mg} / \mathrm{dL}$ $(482 \mathrm{mmol} / \mathrm{L})[14,25]$. In consistence with our findings, these data suggest that longstanding, untreated hyperuricemia might cause joint complaints, (e.g. unspecific pain), even if asymptomatic, probably presenting as diverse and unspecific pain. Dalbeth and coworkers introduced a new staging system for gout dividing asymptomatic hyperuricemia in two stages: hyperuricemia with and without crystal deposition [28]. Considering our findings and those of others crystal depositions should no longer be staged as asymptomatic. In this context, the sudden rise in patients with joint pain from $30.8 \%$ to $60.9 \%$ between urate levels 5.0 and $5.5 \mathrm{mg} / \mathrm{dL}$ is particularly noteworthy and may be indicative of a possible need to correct established norm values. Randomized controlled trials are required to investigate whether urate lowering therapy has a positive effect on patients with hyperuricemia and unspecific musculo-skeletal problems.

The study has several limitations that need to be addressed. The patient reported outcome of pain is subjective and may lead to an over or underrepresentation of actual results. This cross-sectional study was carried out in a single center, therefore center bias cannot be ruled out. However, in order to minimize bias, laboratory check-ups were performed by residents who had little contact with the patients before the examination. On purpose, we forewent the use of a validated pain inventory as usually applied in pain clinics and pain studies, because only a few patients had these included in their routine check-up examination. Furthermore, there might have been a preselection in the sense of predominately pain oriented or pain-focused patients. Imaging to detect uric acid deposits in effected joints associated with pain was not performed.

Overall, the large number of patients forms a solid data base, and the statistics performed indicate that the observed association between urate levels and musculo-skeletal pain was not random.

\section{CONCLUSION AND TRIAL REGISTRATION}

In this population of generally healthy subjects presenting for their annual routine check-up, results indicate the possibility of a significant impact of urate levels on joint pain.

The increasing evidence showing depositions at elevated urate levels without a previous gout attack should stimulate further discussion whether start of gout management should be started earlier. Randomized controlled trials should be undertaken to clarify the link between elevated urate levels, monosodium urate depositions and discomfort in the patients.

This study was reviewed and approved by federal state law established Ethics Committees Counselling (reference no. OB.99).

\section{CONFLICT OF INTEREST}

The authors confirm that this article content has no conflict of interest.

\section{ACKNOWLEDGEMENTS}

This study was funded by Hexal AG and Berlin-Chemie AG.

\section{REFERENCES}

[1] Zhang W, Doherty M, Pascual E, et al. EULAR evidence based recommendations for gout. Part I: Diagnosis. Report of a task force of the Standing Committee for International Clinical Studies Including Therapeutics (ESCISIT). Ann Rheum Dis 2006; 65(10): 1301-11. [http://dx.doi.org/10.1136/ard.2006.055251] [PMID: 16707533] 
[2] Gabriel SE, Michaud K. Epidemiological studies in incidence, prevalence, mortality, and comorbidity of the rheumatic diseases. Arthritis Res Ther 2009; 11(3): 229. [http://dx.doi.org/10.1186/ar2669] [PMID: 19519924]

[3] Perez-Ruiz F. Treating to target: a strategy to cure gout. Rheumatology (Oxford) 2009; 48(Suppl. 2): ii9-14. [http://dx.doi.org/10.1093/rheumatology/kep087] [PMID: 19447780]

[4] Fiddis RW, Vlachos N, Calvert PD. Studies of urate crystallisation in relation to gout. Ann Rheum Dis 1983; 42(Suppl. 1): 12-5. [http://dx.doi.org/10.1136/ard.42.Suppl_1.12] [PMID: 6615025]

[5] Zhang W, Doherty M, Bardin T, et al. EULAR evidence based recommendations for gout. Part II: Management. Report of a task force of the EULAR Standing Committee for International Clinical Studies Including Therapeutics (ESCISIT). Ann Rheum Dis 2006; 65(10): 1312-24. [http://dx.doi.org/10.1136/ard.2006.055269] [PMID: 16707532]

[6] Jordan KM, Cameron JS, Snaith M, et al. British society for rheumatology and british health professionals in rheumatology guideline for the management of gout. Rheumatology (Oxford) 2007; 46(8): 1372-4. [http://dx.doi.org/10.1093/rheumatology/kem056a] [PMID: 17522099]

[7] Khanna D, Fitzgerald JD, Khanna PP, et al. 2012 American College of Rheumatology guidelines for management of gout. Part 1: systematic nonpharmacologic and pharmacologic therapeutic approaches to hyperuricemia. Arthritis Care Res (Hoboken) 2012; 64(10): 1431-46. [http://dx.doi.org/10.1002/acr.21772] [PMID: 23024028]

[8] Abeles AM. Hyperuricemia, gout, and cardiovascular disease: An update. Curr Rheumatol Rep 2015; 17(13)

[9] Duskin-Bitan H, Cohen E, Goldberg E, et al. The degree of asymptomatic hyperuricemia and the risk of gout. A retrospective analysis of a large cohort. Clin Rheumatol 2014; 33(4): 549-53. [http://dx.doi.org/10.1007/s10067-014-2520-7] [PMID: 24522482]

[10] McCarty DJ. Gout without hyperuricemia. JAMA 1994; 271(4): 302-3. [http://dx.doi.org/10.1001/jama.1994.03510280064034] [PMID: 8295290]

[11] Neogi T. Asymptomatic hyperuricemia: perhaps not so benign? J Rheumatol 2008; 35(5): 734-7. [PMID: 18464314]

[12] Kanbay M, Jensen T, Solak Y. Uric acid in metabolic syndrome: From an innocent bystander to a central player. Eur J Intern Med 2015. [http://dx.doi.org/10.1016/j.ejim.2015.11.026] [PMID: 26703429]

[13] Khanna D, Fitzgerald JD, Khanna PP, et al. 2012 American College of Rheumatology guidelines for management of gout. Part 1: systematic nonpharmacologic and pharmacologic therapeutic approaches to hyperuricemia. Arthritis Care Res (Hoboken) 2012; 64(10): 1431-46. [http://dx.doi.org/10.1002/acr.21772] [PMID: 23024028]

[14] Pineda C, Amezcua-Guerra LM, Solano C, et al. Joint and tendon subclinical involvement suggestive of gouty arthritis in asymptomatic hyperuricemia: an ultrasound controlled study. Arthritis Res Ther 2011; 13(1): R4. [http://dx.doi.org/10.1186/ar3223] [PMID: 21241475]

[15] Wolfram G, Husemeyer IM. Abwechslungsreiche Diät bei Gicht. $1^{\text {st }}$ ed. Stuttgart: Trias 1999.

[16] Andersson HI, Leden I. Serum uric acid predicts changes in reports of non-gouty chronic pain: a prospective study among women with inflammatory and non-inflammatory pain. Rheumatol Int 2012; 32(1): 193-8. [http://dx.doi.org/10.1007/s00296-010-1600-5] [PMID: 20803018]

[17] Perez-Ruiz F, Martinez-Indart L. Toheous gout and high level of hyperuricaemia are both associated with increased risk of mortality in patients with gout. Ann Rheum Dis 2014; 73(1): 177-82.

[http://dx.doi.org/10.1136/annrheumdis-2012-eular.1785] [PMID: 23313809]

[18] Lottmann K, Chen X, Schädlich PK. Association between gout and all-cause as well as cardiovascular mortality: a systematic review. Curr Rheumatol Rep 2012; 14(2): 195-203. [http://dx.doi.org/10.1007/s11926-011-0234-2] [PMID: 22350606]

[19] Stack AG, Hanley A, Casserly LF. Independent and conjoint associations of gout and hyperuricaemia with total and cardiovascular mortality 2013. Q J Med 2013; 106: 647-58. [http://dx.doi.org/10.1093/qjmed/hct083]

[20] Toda A, Ishizaka Y, Tani M, Yamakado M. Hyperuricemia is a significant risk factor for the onset of chronic kidney disease. Nephron Clin Pract 2014; 126(1): 33-8. [http://dx.doi.org/10.1159/000355639] [PMID: 24434843]

[21] Kanbay M, Yilmaz MI, Sonmez A, et al. Serum uric acid independently predicts cardiovascular events in advanced nephropathy. Am J Nephrol 2012; 36(4): 324-31. [http://dx.doi.org/10.1159/000342390] [PMID: 23007099]

[22] Ito H, Abe M, Mifune M, et al. Hyperuricemia is independently associated with coronary heart disease and renal dysfunction in patients with type 2 diabetes mellitus. PLoS One 2011; 6(11): e27817. [http://dx.doi.org/10.1371/journal.pone.0027817] [PMID: 22125626]

[23] Johnson RJ, Nakagawa T, Jalal D, Sánchez-Lozada LG, Kang DH, Ritz E. Uric acid and chronic kidney disease: which is chasing which? Nephrol Dial Transplant 2013; 28(9): 2221-8. 
[http://dx.doi.org/10.1093/ndt/gft029] [PMID: 23543594]

[24] Levy GD, Rashid N, Niu F, Cheetham TC. Effect of urate-lowering therapies on renal disease progression in patients with hyperuricemia. J Rheumatol 2014; 41(5): 955-62. [http://dx.doi.org/10.3899/jrheum.131159] [PMID: 24692523]

[25] Reuss-Borst MA, Pape CA, Tausche AK. Hidden gout- Ultrasound findings in patients with musculo-skeletal problems and hyperuricemia. Springerplus 2014; 3: 592 . [http://dx.doi.org/10.1186/2193-1801-3-592] [PMID: 25392770]

[26] Zamudio-Cuevas Y, Diaz-Hernandez C, Pineda C. Molecular basis of oxidative stress in gouty arthopathy. Clin Rheumatol 2015; 34(1): 667-1672.

[27] Chaudhary K, Malhotra K, Sowers J, Aroor A. Uric Acid - key ingredient in the recipe for cardiorenal metabolic syndrome. Cardiorenal Med 2013; 3(3): 208-20 [http://dx.doi.org/10.1159/000355405] [PMID: 24454316]

[28] Dalbeth N, Stamp L. Hyperuricaemia and gout: time for a new staging system? Ann Rheum Dis 2014; 73(9): 1598-600. [http://dx.doi.org/10.1136/annrheumdis-2014-205304] [PMID: 24718961]

(C) Comberg and Schach; Licensee Bentham Open

This is an open access article licensed under the terms of the Creative Commons Attribution-Non-Commercial 4.0 International Public License (CC BY-NC 4.0) (https://creativecommons.org/licenses/by-nc/4.0/legalcode), which permits unrestricted, non-commercial use, distribution and reproduction in any medium, provided the work is properly cited. 